\title{
2064 Fragmented QRS complexes on I 2-lead ECG as a marker of greater myocardial infiltration by cardiac magnetic resonance gadolinium-delayed enhancement images in patients with sarcoidosis
}

\author{
Mohamed Homsi*, Lamaan Alsayed, Dev Vaz, Mithilesh K Das and \\ Jo Mahenthiran
}

Address: Krannert Institute of Cardiology, Indiana University School of Medicine, Indianapolis, IN, USA

* Corresponding author

from I th Annual SCMR Scientific Sessions

Los Angeles, CA, USA. I-3 February 2008

Published: 22 October 2008

Journal of Cardiovascular Magnetic Resonance 2008, I0(Suppl I):A333 doi:10.I I86/I532-429X-I0-SI-A333

This abstract is available from: http://jcmr-online.com/content//0/SI/A333

(c) 2008 Homsi et al; licensee BioMed Central Ltd.

\section{Background}

In our study we demonstrate that presence of either Qwave and or fQRS complexes on a 12-lead ECG in patients with suspected cardiac involvement of sarcoidosis may indicate the presence of greater infiltrative myocardial disease by cardiac magnetic resonance imaging. Fragmented QRS complexes (fQRS) on 12-lead ECG are a marker of greater myocardial scarring and were observed in some sarcoid patients (pts).

\section{Purpose}

To evaluate the significance of presence of fQRS on 12lead ECG compared to Gadolinium-delayed enhancement images (GDE) -Cardiac magnetic resonance (CMR) imaging.

\section{Methods}

Retrospective analysis of pts with established diagnosis with sarcoidosis referred for CMR was done. CMR was performed on 1.5-T Siemens system. GDE images were obtained 10 minutes post contrast injection $(0.1 \mathrm{mmol} /$ $\mathrm{kg}$ dose). Bundle branch block, atrial-ventricular blocks, $\mathrm{Q}$ wave and fQRS were looked for on a 12-lead ECG. Q wave was considered present when it was $>=0.04$ seconds in duration or deeper than one fourth of the $\mathrm{R}$ wave in amplitude. The fQRS on 12-lead ECG was defined by the presence of fragmented QRS, notched R or S wave, or RSR' pattern in at least 2 contiguous leads in one of the major coronary artery territories (LAD: lead V1 to V6, LCx: lead I, aVL and V6, and RCA: lead II, III and aVF). Figure 1.

\section{Results}

12 pts (mean age $52 \pm 11$ year, $42 \%$ male) were studied. fQRS, Q wave and bundle branch block were present in 6 $(50 \%), 2(17 \%)$ and $1(8 \%)$ pts, respectively. $5(45 \%)$ pts had abnormal GDE in CMR suggestive of possible cardiac involvement of sarcoidosis. All pts had midwall GDE except one patient had midwall GDE as well as subenodcardial GDE which represented an old known myocardial infarction. $67 \%$ of pts $(n=4)$ with fQRS had abnormal GDE vs. $17 \%$ of pts $(\mathrm{n}=1)$ without fQRS had abnormal GDE; $p=0.09$. Whereas the abnormal GDE was found in $71 \%$ of pts $(\mathrm{n}=5)$ with either $\mathrm{Q}$ wave or fQRS vs. none $(0 \%)$ of pts without Q wave or fQRS; $p=0.008$.

\section{Conclusion}

The presence of either Q-wave and or fQRS complexes on a 12-lead ECG in patients with suspected cardiac involvement of sarcoidosis may indicate the presence of greater infiltrative myocardial disease by GDE-CMR imaging. 


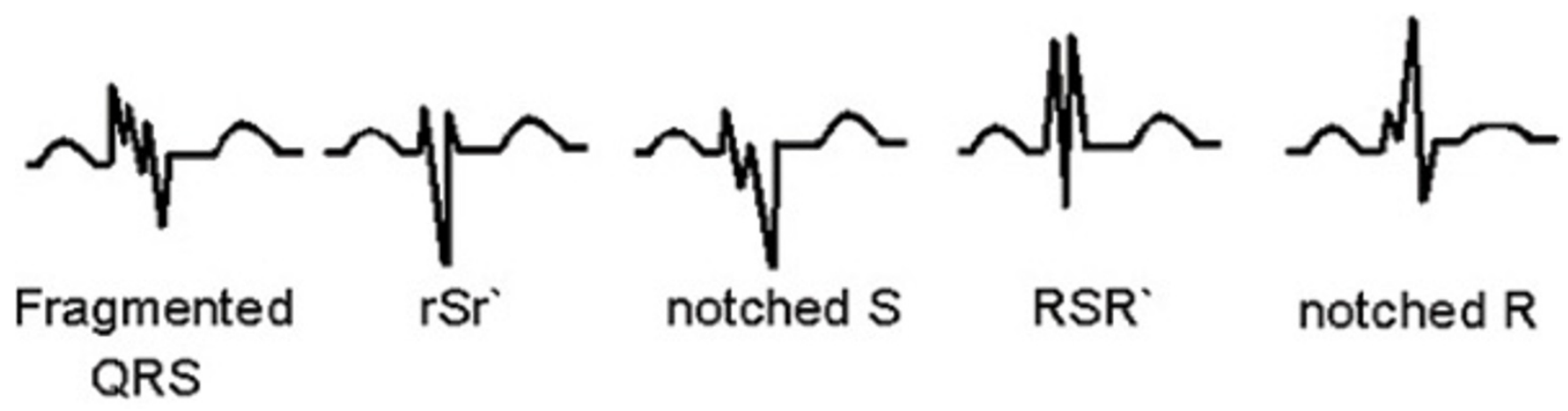

Figure I

Different morphologies of fQRS on I2-lead ECG.

Publish with Bio Med Central and every scientist can read your work free of charge

"BioMed Central will be the most significant development for disseminating the results of biomedical research in our lifetime. "

Sir Paul Nurse, Cancer Research UK

Your research papers will be:

- available free of charge to the entire biomedical community

- peer reviewed and published immediately upon acceptance

- cited in PubMed and archived on PubMed Central

- yours - you keep the copyright 